\title{
Per urethral insertion of foreign body for erotism: case reports
}

\author{
Christy WH Mak, MB, ChB, CL Cho *, FRCSEd (Urol), FHKAM (Surgery), Wayne KW Chan, FRCSEd (Urol), FHKAM (Surgery), \\ Ringo WH Chu, FRCSEd (Urol), FHKAM (Surgery), IC Law, FRCSEd (Urol), FHKAM (Surgery)
}

Division of Urology, Department of Surgery, Kwong Wah Hospital, Yaumatei, Hong Kong

*Corresponding author: chochaklam@yahoo.com.hk

Hong Kong Med J 2019;25:320-2

https://doi.org/10.12809/hkmj177044

\section{Case reports}

\section{Patient 1}

A 31-year-old man presented in December 2016 with a 1-day history of retained foreign body in the urinary bladder. He reported regular insertion of a commercially available silicone urethral instrument for autoerotism. He customarily evacuated the instrument by voiding but he had failed to do so on this occasion. There was no dysuria, haematuria, abdominal pain or fever. Laboratory parameters were within normal limits and no foreign body could be identified on X-ray. Flexible cystoscopy revealed an $18-\mathrm{cm}$ length of soft tubing inside the urinary bladder (Fig 1a). Successful retrieval was achieved with endoscopic forceps. He was discharged home on the same day.

\section{Patient 2}

A 57-year-old man was admitted in January 2017 with a 6-week history of intermittent fever and right scrotal swelling. He had no lower urinary tract symptoms except for a yellowish urethral discharge. He revealed a history of regular per urethral insertion of self-customised plastic tubing with plastic beads inside the lumen for sexual gratification (Fig $1 \mathrm{~b}$ and c). The patient cleaned the tubing with tap water after each use. Physical examination revealed a tender and swollen right testis with fluctuance, indicative of abscess formation. Serum white blood cell count was $15.1 \times 10^{9} / \mathrm{L}$. Drainage of scrotal abscess was performed and the patient was discharged home with a course of antibiotics.

\section{Patient 3}

A 55-year-old woman was admitted in May 2017 with a 1-day history of retained vibrator in the urinary bladder. The vibrator was inserted into her urethra during sexual activity with her husband. She complained of subsequent dysuria and haematuria. Serum white blood cell count was mildly elevated. $\mathrm{X}$-ray revealed a $12.5-\mathrm{cm}$ foreign body in the pelvic region (Fig 2). Retrieval of the vibrator via flexible cystoscopy failed owing to inadequate size and strength of the cystoscopic forceps. Semi-rigid ureteroscopy was used to locate the vibrator with Kocher forceps placed alongside for removal. Removal of the vibrator was achieved and the patient was discharged home with antibiotics.

\section{Discussion}

Polyembolokoilamania refers to the act of inserting a foreign body into body orifices. Urethral polyembolokoilamania is not uncommon and several cases have been reported in the literature. Different types of foreign bodies have been reportedly introduced into the urethra, including electric wires, thermometers, hairpins, toothpicks, eyeglass rims, straws, pencils, paperclips, and fishhooks. ${ }^{1,2}$ Autoerotism is one of the most common reasons given for polyembolokoilamania, although others include curiosity, psychiatric illness, iatrogenic causes, and an attempt to relieve urinary symptoms. ${ }^{3}$ The prevalence of the condition is unknown and probably underreported owing to embarrassment of patients so a high index of suspicion and targeted history taking play an important role in correctly diagnosing the condition. There are reports suggesting the possible role of psychiatric assessment in revealing an underlying psychiatric disease and preventing repeated occurrences of foreign body insertion. ${ }^{4}$ Nonetheless psychiatric assessment is not considered mandatory for all patients. The prevalence of psychiatric diagnoses in this group of patients and the efficacy of psychiatric interventions are still largely unknown. There is no consensus on the role of psychiatric consultation for patients with urethral polyembolokoilamania.

Various complications may arise from insertion of foreign bodies per urethra including urinary tract infection, urethral injury and, most commonly, retained foreign body. The presentation of retained foreign body in the lower urinary tract varies widely although dysuria and haematuria are the most common presentation. ${ }^{3,5}$ The severity of the condition depends on the nature of the foreign body and, more importantly, time to medical attention. Early diagnosis and removal of the foreign body are of prime importance. In our case series, patients 1 and 3 sought early medical advice and experienced 


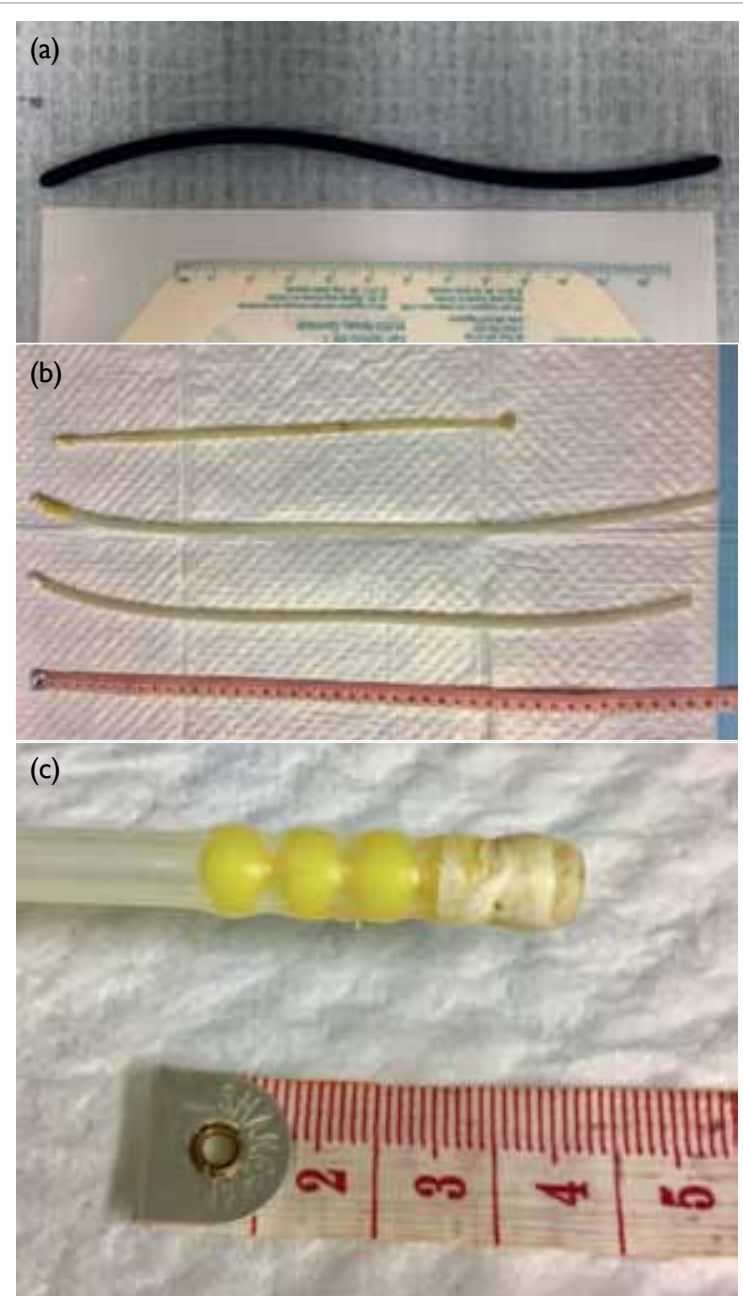

FIG I. (a) An I8-cm-long commercially available silicone urethral instrument was retrieved from the urinary bladder of patient I. (b) Self-made plastic tubing of patient 2. (c) Close-up of the plastic beads inside the plastic tubing of patient 2

no complications. Late presentation may lead to complications such as recurrent urinary tract infection and urolithiasis or, less commonly, erosion of foreign body to adjacent organs. ${ }^{5}$ Presenting time is highly variable, ranging from hours to months. ${ }^{1}$ Delay in seeking medical consultation may stem from ignorance, psychiatric illness, or embarrassment. ${ }^{1}$

$\mathrm{X}$-ray is often performed but is helpful in identifying only radio-opaque objects. Instead, flexible cystoscopy should be performed early for all patients with suspected retained foreign body in the lower urinary tract, in view of the relative simplicity and low risk of the procedure. Flexible cystourethroscopy can achieve accurate diagnosis and treatment simultaneously. A high success rate of $50 \%$ to $93 \%$ has been reported for endoscopic removal of foreign body. ${ }^{1,3}$ Computed tomography scan is indicated only in patients with peritonitis or suspected foreign body migration to adjacent organs. $^{3}$

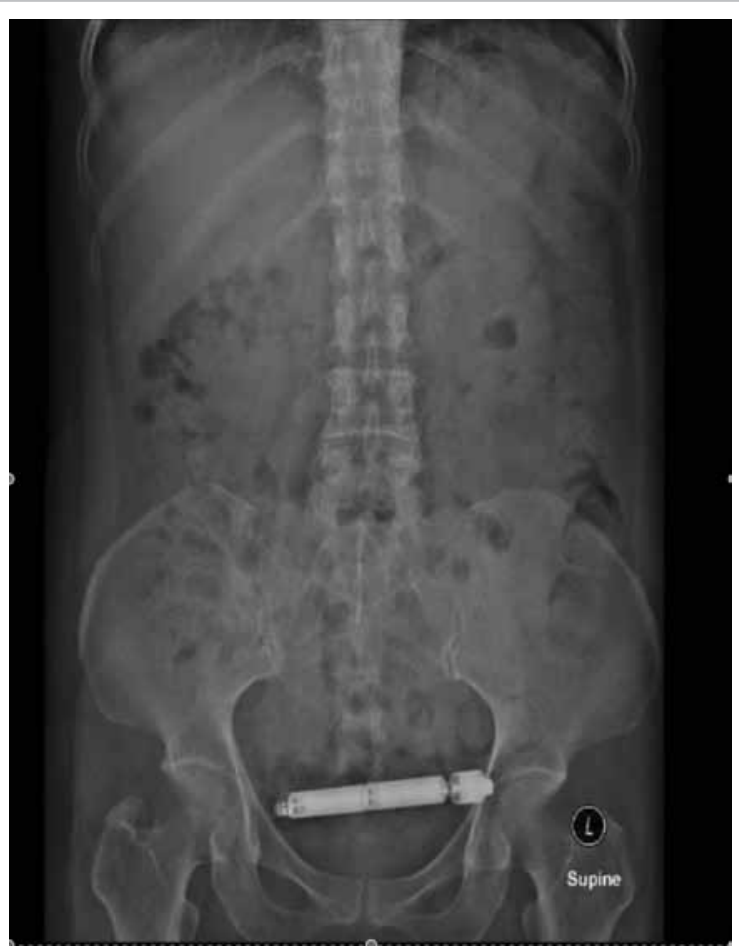

FIG 2.X-ray shows vibrator in pelvic region of patient 3

A surgical approach for retrieval of retained foreign body depends on the size, shape and location of the object. Simple measures, for example milking of the urethra, usually have a high success rate for expulsion of foreign body located in the distal penile urethra. ${ }^{3}$ Invasive approaches including open cystostomy and perineal urethrostomy have been reported when retrieving larger size, encrusted, or sharp objects after failed endoscopic manoeuvres. ${ }^{1}$ More complex procedures, including laparotomy and urinary diversion may be indicated for complicated cases. The surgical approach should be individualised. ${ }^{5}$

Insertion of foreign bodies into the urethra is predominantly reported in men. Palmer et $\mathrm{al}^{3}$ reported that $97 \%$ of their patients were men during their 15 years' experience of managing self-insertion of urethral foreign bodies and six of their 27 patients had a recurrent history. This male-dominated phenomenon is also evidenced by the wide availability of male sexual urethral instruments in shops and online platforms. These instruments, namely urethral sounds and dilators, generally constitute a 15 - to 20$\mathrm{cm}$-long stainless steel or silicone tube that is used for deep penetration to the level of the prostatic urethra. Deep prostate stimulation-associated orgasms are thought to be more intense than those with direct penile stimulation, and involve more pelvic muscle contractions. ${ }^{6}$ However, hygiene of the instrument is a concern as instrumentation without 
proper disinfection subjects a patient to further risk of infective complications.

In conclusion, insertion of a foreign body into the lower urinary tract for erotism is not uncommon, especially in men. Early diagnosis and endoscopic removal of the foreign body achieve a high success rate and should be considered the initial management. Delayed presentation may lead to complications that require further imaging and more complex surgical procedures.

\section{Author contributions}

All authors had full access to the data, contributed to the study, approved the final version for publication, and take responsibility for its accuracy and integrity.

Concept or design: CL Cho.

Acquisition of data: CWH Mak.

Analysis or interpretation of data: CL Cho, CWH Mak.

Drafting of the article: CWH Mak, CL Cho.

Critical revision for important intellectual content: All authors.

\section{Conflicts of interest}

The authors have disclosed no conflict of interest.

\section{Funding/support}

This research received no specific grant from any funding agency in the public, commercial, or not-for-profit sectors.

\section{Ethics approval}

Verbal consent was obtained for the purpose of case study.

\section{References}

1. Rafique M. Intravesical foreign bodies: review and current management strategies. Urol J 2008;5:223-31.

2. Rahman NU, Elliott SP, McAninch JW. Self-inflicted male urethral foreign body insertion: endoscopic management and complications. BJU Int 2004;94:1051-3.

3. Palmer CJ, Houlihan M, Psutka SP, Ellis KA, Vidal P, Hollowell CM. Urethral foreign bodies: clinical presentation and management. Urology 2016;97:257-60.

4. Unruh BT, Nejad SH, Stern TW, Stern TA. Insertion of foreign bodies (polyembolokoilamania): underpinnings and management strategies. Prim Care Companion CNS Disord 2012;14(1). pii: PCC.11f01192.

5. Cury J, Coelho RF, Srougi M. Retroperitoneal migration of a self-inflicted ballpoint pen via the urethra. Int Braz J Urol 2006;32:193-5.

6. Alwaal A, Breyer BN, Lue TF. Normal male sexual function: emphasis on orgasm and ejaculation. Fertil Steril 2015;104:1051-60. 